\title{
LA CIENCIA NOS ENSEÑA A AMAR \\ LA NATURALEZA
}

Hace cinco años apareció la revista científica In C rescendo. Se dio a luz una nueva manera de expresar el conocimiento de los docentes. Era la oportunidad de expresar la investigación como un factor sustantivo de la universidad.

Nació con la intención de poner de manifiesto aquello que los docentes, fieles a la naturaleza de su misión, profundizan, reflexionan y proponen. Los resultados de sus investigaciones y estudios encontraron un espacio para compartir los conocimientos con el mundo académico y la sociedad interesada en profundizar ulteriores investigaciones.

H an sido años no solo apasionantes sino serenos y dinámicos, con sueños de libertad que profundizaron en la ciencia y en los valores humanos; sin embargo, tendremos que hacer un al to mientras pasa la noche oscura, preámbulo de un nuevo amanecer.

Precisamente en estos tiempos en que se intenta hacer prevaler el utilitarismo y la afiebrada competencia por la tecnología, el mundo nos ofrece un hombre que vive y busca la verdad. Es Francisco, quien resalta el don de ciencia. Él nos dice que cuando se habla de ciencia, el pensamiento va inmediatamente a la capacidad del hombre de conocer siempre mejor la realidad que lo circunda y de descubrir las leyes que regulan la naturaleza y el universo. Pero la ciencia que viene del Espíritu Santo no se limita al conocimiento humano: es un don especial que nos lleva a percibir, a través de la creación, la grandeza y el amor de Dios y su relación profunda con cada criatura.

Nos hacemos eco de este pensamiento que nos recuerda que cuando nuestros ojos son iluminados por el Espíritu Santo, se abren a la contemplación de Dios en la belleza de la natural eza y en la grandiosidad del cosmos, y nos llevan a descubrir cómo cada cosa nos habla de Él y de su amor. ¡Todo esto suscita en nosotros gran estupor y un profundo sentido de gratitud!

La profundización en la ciencia no nos exime de la sensación que sentimos cuando admiramos una obra de arte o cualquier maravilla que sea fruto del ingenio y de la creatividad del hombre: el Espíritu nos lleva a alabar a Dios desde lo profundo del corazón y a reconocer, en todo lo que tenemos y somos, un don inestimable de Dios y un signo de su infinito amor por nosotros. 
En el libro sagrado se pone en evidencia que Dios se complace de su creación, subrayando repetidamente la belleza y la bondad de cada cosa. Si Dios ve que la creación es una cosa buena y bella, también nosotros hemos de tener esta actitud: de ver que la creación es cosa buena y bella. Y con el don de la ciencia, por esta belleza alabamos a Dios y le agradecemos por habernos dado ¡tanta belleza!

Y cuando Dios terminó de crear al hombre no dijo "vio que era cosa buena"; dijo que era "muy buena", nos acerca a Él. Y a los ojos de Dios nosotros somos lo más bello, lo más grande, lo más bueno de la creación.

Francisco, el hombre que ha dado un nuevo impulso de novedad al mundo, insiste que el don de la ciencia nos pone en profunda sintonía con la Creación y nos hace partícipes de la limpidez de su mirada y de su juicio. Y en esta perspectiva logramos captar en el hombre y en la mujer el culmen de la creación, como cumplimiento de un designio de amor que está impreso en cada uno de nosotros y que nos hace reconocernos como her manos y hermanas.

El espíritu de la verdad nos impuso a sentir todo como fuente de serenidad y de paz y hace del cristiano un gozoso testigo de Dios, en las huellas de San F rancisco de Asís y otros muchos santos que supieron alabar y cantar su amor a través de la contemplación de la creación. Al mismo tiempo, sin embargo, el don de ciencia nos ayuda a no caer en algunas actitudes excesivas o equivocadas.

El espíritu cientificista corre el riesgo de considerarnos dueños de la creación. Porque la creación no es una propiedad que podemos gobernar a voluntad; tampoco es una propiedad de solo algunos pocos: la creación es un regalo, un don maravilloso que Dios nos ha dado, para que lo cuidemos y lo utilicemos en beneficio de todos con gran respeto y gratitud.

Este espíritu positivista defiende una actitud equivocada como tentación de quedarnos en las criaturas, como si estas pudieran ofrecer la respuesta a todas nuestras expectativas. Y el Espíritu Santo con el don de la ciencia nos ayuda a no caer en esto.

Pero Francisco nos dice: yo quisiera volver a la primera vía equivocada "cuidar la creación", no "adueñarse de la creación". D ebemos cuidar la creación, es un don que el Señor nos ha dado, ies el regalo de Dios a nosotros! Nosotros somos custodios de la creación, pero cuando nosotros explotamos la creación, idestruimos el signo de amor de Dios! 
Destruir la creación es decir a Dios: "no me gusta, esto no es bueno". ¿Y qué te gusta a ti? Me gusto a mí mismo: ¡Este es el pecado! La custodia de la creación es precisamente la custodia del don de Dios.

Hemos de respetar la creación. Custodiarla, porque si nosotros destruimos la creación, la creación nos destruirá. Este cuidado exige en primer lugar, el cuidado y respeto por la persona humana, creada a imagen de Dios. Respetar su identidad, comprender su realidad existencial y acompañarla para que logre sus nobles ideales y legítimas aspiraciones.

L a comunidad científica, sin perder el rigor de su método, ha de reflexionar sobre el don de la ciencia para entender bien que la creación es el más hermoso regalo de $D$ ios.

Juan Roger Rodríguez Ruiz J EFE DE PUBLICACIONES

\section{LAS REVISTAS DE INVESTIGACIÓN Y LA MISIÓN DE LA UNIVERSIDAD}

En estos tiempos de masificación y proliferación universitaria, cuyo signo más visible, evidente y casi único, es la formación profesional y el aspecto lectivo, es lamentable comprobar cómo, pese a lo proclamado y pregonado, la investigación científica no alcanza, ni en magnitud, ni en extensión, ni en profundidad, la consideración y atención logradas por la actividad característica de la enseñanza-aprendizaje.

En el panorama impactante, incluso por la presencia de universidades en lugares jamás imaginados, con carencia de recursos, precaria infraestructura y con nivel académico discutible o muy bajo, no aparece de manera ostensible, el producto de las investigaciones; y los pocos autores que investigan y producen ciencia y cultura no encuentran el medio difusor disponible. Por eso las universidades peruanas no aparecen en los rankings internacionales que dan cuenta de las instituciones que realizan y producen investigación científica.

Varias universidades se afanan y fundan sus revistas de investigación, las cuales, una vez que empiezan a editarse rápidamente entran en un proce- 